\section{Diagnóstico y tratamiento de la hidatidosis}

E sta ciclozoonosis parasitaria, producida por el estado larval de cestodos del género Echinococcus, cuya especie granulosus es la única identificada en Chile y cuyo hospedero definitivo y habitual es el perro, sigue afectando incidentalmente al Hombre por el desconocimiento de la población sobre esta infección parasitaria y su mecanismo de transmisión. Si bien su incidencia ha ido en descenso en las últimas décadas, ésta se mantuvo estable entre los años 1998 y 2002 con una tasa de 2,2/100.000 habitantes, notándose un descenso significativo a 0,8 / 100.000 el año 2003 (Depto. de Epidemiología, MINSAL). La mayoría de los afectados procede de las regiones $\mathrm{IX}^{\mathrm{a}}, \mathrm{X}^{\mathrm{a}}$ y XI ${ }^{\mathrm{a}}$. Sin embargo, existe una subnotificación, como ha sido demostrado en estudios serológicos poblacionales y en autopsias.

Al desarrollarse la larva o hidátide en el hospedero intermediario, generalmente ovinos, bovinos y porcinos y accidentalmente en el Hombre, se produce una reacción fibrosa del tejido conectivo circundante, denominado adventicia; transformándose en quiste hidatídico, pudiendo el individuo permanecer asintomático por meses o años y manifestándose clínicamente cuando alcanza un tamaño tal que desencadena síntomas por compresión en el órgano afectado o cuando se complica (infección o rotura).

Frecuentemente en el Hombre, niños o adultos, el quiste hidatídico es único, siendo menos habitual la presencia de más de un quiste. Éste puede sufrir procesos degenerativos, calcificarse, romperse originando serias complicaciones o infectarse, transformándose en un absceso; situación en la cual la larva muere.

El diagnóstico de sospecha es a través de imágenes, apoyado en los antecedentes epidemiológicos y serológicos. Se debe plantear frente a toda tumoración de tipo quística en cualquier localización, principalmente hígado y pulmón. La investigación de antecedentes epidemiológicos (lugar de residencia, contacto con perros, principalmente en zonas rurales, antecedentes de otros familiares afectados) es de gran utilidad.

Las diferentes técnicas por imágenes, utilizadas en la actualidad, siguen siendo las herramientas más útiles para diagnosticar el principal elemento de sospecha. En el hígado, la ecografía, el eco-doppler, la cintigrafía, la tomografía axial computada (TAC) y la resonancia magnética, dan una aproximación bastante certera. La Rx simple de tórax en dos planos, en ocasiones, ofrece imágenes patognomónicas (neumoperiquiste, doble arco, imagen del camalote). Es indudable el aporte que significan otras técnicas imagenológicas más sofisticadas, pero dependerá de su disponibilidad.

El diagnóstico inmunológico específico es de gran utilidad cuando se trata de descartar lesiones tumorales y/o lesiones quísticas producidas por el parásito. Se efectúa a través de la detección de anticuerpos específicos de clase $\operatorname{IgG}$ o IgE contra el antígeno hidatídico, en el suero del paciente.

Se han desarrollado numerosas técnicas tratando de lograr una mejor sensibilidad y especificidad. Ninguna de las pruebas es satisfactoria individualmente y debieran utilizarse dos o más ensayos. Uno sensible pero poco específico como la hemaglutinación indirecta (HIA), con una doble difusión en gel o una inmunoelectroforesis con detección de arco $5^{\circ}$ (DD5) como confirmación. Tienen una elevada especificidad cuando existe el arco 5 (cercana a 98\%), pero su sensibilidad no supera el $60 \%$. De este modo, una reacción negativa no descarta el diagnóstico.

Entre las otras técnicas desarrolladas, destaca la detección de IgG e IgE mediante ELISA, con una sensibilidad aproximada de $86 \%$ y una especificidad de $93 \%$.

El western blot está basado en los mismos principios que el test de ELISA con una sensibilidad similar y una especificidad de $96 \%$.

La identificación de antígenos circulantes específicos es un avance reciente que beneficia la detección del quiste hidatídico, no influenciado por su ubicación y que tendría capacidad para evaluar el seguimiento de paciente en tratamiento. Estos antígenos se detectan por la unión con anticuerpos, poli o monoclonales, también específicos. El nivel de antigenemia generalmente es bajo, a menos que los quistes sean grandes, fértiles y que se hayan roto (más proclives a perder antígenos). Demostró una relativa baja sensibilidad (40\%), pero con una especificidad del $90 \%$.

El inmunodiagnóstico es de bastante utilidad frente a imágenes sospechosas o frente al diagnóstico diferencial de una lesión tumoral y debiera solicitarse de rutina, con las limitaciones descritas. Las reacciones serológicas se negativizan en uno a cuatro años post cirugía, cuando no existe recidiva.

El diagnóstico parasitológico de certeza se obtiene con la presencia de ganchitos, escólices o membranas, en la expectoración, bilis u orina, cuando el quiste se ha roto o en el líquido proveniente de una tumoración quística obtenido durante un acto quirúrgico. En la actualidad, se efectúa punción percutánea de un quiste con aguja fina guiada bajo ecografía o TAC; técnica no exenta de riesgos que, además, se ha utilizado para efectuar tratamientos, como se señalará más adelante. El examen del líquido o de las membranas es, además, de gran importancia para conocer la fertilidad del quiste, especialmente cuando éste se ha roto durante el acto quirúrgico o la mencionada punción, porque crea la necesidad de tratamiento médico para evitar recidivas.

La cirugía sigue siendo el tratamiento de elección; la técnica quirúrgica a emplear y la vía de abordaje dependerá de la localización, del estado del quiste, de su tamaño y de la experiencia del equipo quirúrgico. 
Existen tratamientos alternativos y/o complementarios como son el empleo de derivados imidazólicos, siendo en la actualidad más utilizados los de tercera generación. El tratamiento con albendazol ha demostrado resultados promisorios y tiene sus mayores indicaciones en hidatidosis múltiples, en pacientes de alto riesgo quirúrgico o inoperables, en hidatidosis ósea, cuando el paciente rechaza la cirugía y como quimioprofilaxis pre y postoperatoria. Se recomienda su empleo durante cuatro a seis semanas repitiendo las curas tres a seis veces. Como quimioprofilaxis se ha empleado durante cuatro días en el preoperatorio y entre uno y tres meses en el post operatorio, en especial cuando se ha derramado líquido hidatídico durante el acto quirúrgico y el estudio de fertilidad es positivo.

Albendazol actúa uniéndose a la $\beta$-tubulina parasitaria inhibiendo la polimerización de la tubulina y el transporte de glucosa microtúbulo dependiente, causando depleción del glucógeno, alteraciones degenerativas en el retículo endoplásmico y mitocondrias de la capa germinativa, aumentando el número de lisosomas y autolisis celular. Aparentemente, estos fármacos primero actuarían sobre las capas externas del quiste, llevando a una marcada reacción inflamatoria que alteraría la homeostasis parasitaria y provocaría la pérdida gradual de vitalidad de los protoescólices y la capa germinal.

Una de las mayores dificultades a resolver es la definición de criterios que permitan identificar el efecto parasiticida y la determinación de la duración adecuada del tratamiento para que resulte exitoso.

Otra opción para el tratamiento de casos de hidatidosis, especialmente hepática, es la técnica de punción, aspiración, instilación y reaspiración (PAIR). Las siglas de esta técnica derivan de los pasos involucrados en este procedimiento. La punción se efectúa bajo monitoreo ultrasonográfico, luego se aspira el contenido y se instilan agentes escolicidas dentro de la cavidad para luego reaspirar después de diez minutos de dejar actuar la solución. Se ha empleado, asociada o no, a tratamiento médico.

Esta técnica, poco invasora, ha demostrado tener excelentes resultados en pacientes en los cuales la cirugía no era posible o estaba contraindicada. Según normas de la OMS para el tratamiento de hidatidosis, previo a la realización de la técnica PAIR, se debe administrar por el lapso de cuatro a siete días, benzimidazoles, como así también durante un mes (albendazol) o tres meses (mebendazol) luego de concluido el procedimiento. El objetivo de la terapia con benzimidazoles es fundamentalmente profiláctico, es decir, está destinado a proteger al paciente en caso de que se produzca escape del contenido del quiste.

Con esta técnica, el tiempo de hospitalización es menor, lo que conlleva un menor gasto en comparación con la cirugía.

En los últimos años, han surgido líneas de investigación para desarrollar nuevas herramientas terapéuticas para el tratamiento de la hidatidosis, siendo una de ellas el desarrollo de una vacuna para controlar la infección en los animales que son hospederos intermediarios.

La hidatidosis es una enfermedad evitable con medidas preventivas fundamentales y simples que se inician con la educación sanitaria del Hombre de cualquier edad, lugar y nivel cultural. El objetivo fundamental es dar a conocer el problema para lograr cambios, entre los cuales destaca el buen aseo de las manos antes de ingerir alimentos y muy en especial, después de acariciar un perro, el lavado de frutas y verduras antes de consumirlas, el beber agua apta para su consumo, el no dar a ingerir a los perros vísceras crudas de animales con las llamadas "bolsas de agua".

Junto con esta educación es indispensable otras medidas, como son el adecuado control médico-veterinario de los animales beneficiados para el consumo, el tratamiento periódico y controlado de los perros en los lugares más afectados del país y mantener una vigilancia epidemiológica constante y activa.

Patricia Muñoz $C$ del $V$.

Hospital Militar del General Luis Felipe Brieba Arán Universidad de Los Andes

E-mail:pmunoz@hosmil.cl

\section{Referencias}

1.- Vargas D, Gabbe G, Castro R, et al. Implementation of an ELISA test for the diagnosis of human hydatid disease. Rev Parasitol 1995; 55: 223-6.

2.- De Rycke P, Apt W, Campano S, Thompson R. Many facets of equinococcosis/hydatidosis. Parasitol Today 1995; 12: 29.

3.- Nasseri Moghaddam S, Abrishami A, Malekzadeh R. Percutaneous needle aspiration, injection, and reaspiration with or without benzimidazole coverage for uncomplicated hepatic hydatid cysts [Reviews] The Cochrane Library, Copyright 2006, The Cochrane Collaboration Volume (3), 2006

4.- Anadol D, Ozcelik U, Kiper N, Gocman A. Treatment of hydatid disease. Paediatr Drugs 2001; 3: 123-35

5.- Siracusano A, Ortona E, Rigano R. Molecular and cellular tools in human cystic echinococcosis. Curr Drug Targets Immune
Endocr Metabol Disord 2002; 2: 235-45.

6.- Ito A. Serologic and molecular diagnosis of zoonotic larval cestode infections. Parasitol Int 2002; 51: 221-35.

7.- WHO Informal Working Group on Echinococcosis, Guidelines for treatment of cystic and alveolar echinococcosis in humans. Bull WHO 1996; 74: 231-42.

8.- Salama H, et al. Diagnosis and treatment of hepatic hydatid cysts with the aid of echoguided percutaneous cyst puncture. Clin Infect Dis 1995; 21: 1372-6. 